\title{
Prevalence of antibody titre in healthy individual and enteric fever patients in Owerri, Nigeria
}

\author{
Ibegbulam-Njoku Peace N. ${ }^{1 \star}$, Chijioke-Osuji C.C. ${ }^{2}$ and Duru F.C. ${ }^{1}$ \\ ${ }^{1}$ Department of Microbiology, Michael Okpara University of Agriculture, Umudike, Abia State, Nigeria. \\ ${ }^{2}$ Theoretical and Applied Biology Department of Kwame Nkrumah University of Science and Technology, \\ Kumasi, Ghana.
}

Received 13 December, 2013; Accepted 5 May, 2014

\begin{abstract}
The aim of this study was to establish the prevalence of enteric fever amongst individuals in Owerri municipal area of Imo state. The study shows that $61(24.4 \%)$ patients had typhoid fever based on clinical examination and serological test results (Widal test). It was observed that prevalence of enteric fever was high among the patients of age group 26 to 35 years (44.3\%). Similarly, prevalence of typhoid fever was higher in females with $38(62.7 \%)$ than males $23(37.7 \%)$. It was concluded that prevalence of typhoid fever was high among the youths who consume unsafe drinking water and food from outside source. However, the survey revealed that not all medical cases of typhoid fever reported were correct because most private medical clinics do not carry out tube agglutination test on their patients due to lack of medical facilities and poverty level in the country.
\end{abstract}

Key words: Antibody titre, typhoid, enteric fever, drinking water.

\section{INTRODUCTION}

Enteric fever is an acute systemic infection of humans caused by Salmonella enterica serovar Typhi (S. Typhi) (Olsen et al., 2004) and Salmonella enterica serotype Paratyphi A, B and C (S. Paratyphi A, B and C) also known as non typhoid salmonella (NTS) causing similar type of condition with less severity (Bhan et al., 2005). The fever is a global infectious disease with prevalence in Africa, South America and greatest risk in the Indian subcontinent (Bhutta and Hendricks, 1996; Parry, 2005). The annual incidence of enteric fever is estimated to be about 17 million cases worldwide (world Health Organization (WHO), 2008). In Africa, it has an estimated crude incidence of 362 cases per 100,000 persons per year (Buckle et al., 2012). In most endemic areas, approximately $90 \%$ of enteric fever is typhoid and caused about 216,500 deaths among children and young adults worldwide (Kothari et al., 2008; Yang, 2008).

Typhoid and paratyphoid fever causes serious public health problem in developing countries due to their poor standard of hygiene and unavailability of potable water (Crump et al., 2004; Nicholas et al., 2010). It is mostly encountered in tropical and sub-tropical countries including Nigeria where it constitutes significant sources of morbidities and mortalities (Ibekwe et al., 2008).

These bacteria can survive between days to months in seawater and contaminated eggs, respectively (Elsarnagawy, 1978; Wait and Sobsey, 2001; Kothari et al., 2008). The infectious dose of enteric organisms in

*Corresponding author. E-mail: peacennem@gmail.com. +234 8033603237.

Author(s) agree that this article remain permanently open access under the terms of the Creative Commons Attribution License 4.0 International License 
human can vary between $10^{3}$ to $10^{6}$ organisms when taken orally via ingestions of food or water contaminated with faeces (Kothari et al., 2008). Also, it can be transmitted through recent contact with a typhoid patient or carrier, eating ice cream flavoured iced drinks or food from street vendors and raw fruit and vegetables grown in field fertilized with sewage (Bhan et al., 2005). Infected individuals serve as reservoir for the bacteria and source of infection to others in the transmission mode of enteric fever. Within one week of infection, the bacteria enter into the blood and shed through stool. At the second week, it appears in both stool and urine.

In Nigeria, the facilities for isolation and identification of these organisms in most private hospitals and medical laboratories are rarely available (Onunkwo et al., 2001). Many hospitals in rural areas lack facilities for blood culture, therefore up to $90 \%$ of patients with fever are treated as outpatients. This situation has made it difficult to obtain reliable data from which to estimate the extent of the disease in country. The disease is characterized by malaise, fever, abdominal discomfort, transient rash, splenomegaly, hepatomegaly, bradycardia and leucopenia; the most prominent major complications are intestinal hemorrhage and perforation (Hook and Gurrant, 1987). The standard diagnosis of enteric fever is by isolation of the organism from culture of blood, bone marrow aspirate, stool, bile or urine.

Typical reactions of $S$. enterica serovar Typhi include a characteristic biochemical pattern in triple sugar iron medium which produces acid but without gas, an alkaline slant and a reasonable amount of $\mathrm{H}_{2} \mathrm{~S}$ production tests. Identification is confirmed by serological demonstration of the lipopolysaccharide "O" antigen of group D, protein flagella antigen $\mathrm{Hd}$ and $\mathrm{Vi}$ polysaccharide of capsular antigen (Parry, 2005). This study reports on frequency distribution of healthy individuals against positive typhoid fever cases and distribution frequency of $S$. enterica serovar Typhi / Paratyphi antigens in positive patients. It also establishes the prevalence of enteric fever amongst gender and age distributions.

\section{MATERIALS AND METHODS}

\section{Samples collection}

The blood samples were collected from Private medical centre laboratories, private clinics in Owerri and Federal University of Technology Owerri. Most of these samples collected from the Private clinics and Medical laboratories were those used to investigate suspected cases of "typhoid fever". The samples collected from the university community included those of healthy individuals. The blood samples were collected with sterile bijou bottles, serum later extracted and stored in refrigerator prior to screening. Each serum sample was accompanied by a predesigned questionnaire with the following information - age (5 to 30 years), sex and date of collection. All samples were collected between January and April, 2013. A total of 250 blood samples was collected and investigated. The number of supposed typhoid fever patients collected from various clinics and private medical laboratories was
190 while 60 individuals from the University community donated their blood samples, making up the total of 250 samples used for this research.

\section{Widal agglutination test}

Widal agglutination test was performed using widal agglutination kit (Biotech lab, united states) containing both somatic "O" and flagella "H" antigens of S. Typhi and S. Paratyphi A, B and C. A negative saline control was introduced in each batch of test. The widal test was carried out in three phases namely rapid slide agglutination, tube dilution and confirmatory tube agglutination tests.

\section{Rapid slide agglutination}

All the sera samples were initially analysed for S. Typhi antibodies on a clean greaseless tile. Drop of widal antigen suspension antigens were placed unto undiluted sera samples, mixed by gently rotating the tiles for 1 to $2 \mathrm{~min}$ and observed for agglutination. The sample that showed granules (agglutination) with any of the antigen suspension on the tile was considered positive and set aside for tube agglutination test.

\section{Tube dilution agglutination test}

Dilution of the serum (1:10) was made with the test antigen suspension in test tubes. The presence of positive tube agglutination test necessitated confirmatory test to the determine antibody titre value. The resultant positive sera samples were further tested at $1 / 20,1 / 40,1 / 80,1 / 160$ and $1 / 320$ in $0.8 \%$ normal saline. The tubes were incubated in a water bath at 45 to $50^{\circ} \mathrm{C}$ for $18 \mathrm{~h}$ when somatic "O"antigen was used while the tubes were incubated for one hour at the same temperature when flagella "H"antigen was used. The tube in which there were granules formations were regarded as positive tube agglutination test, while the ones that the suspension remained cloudy gave negative results. A positive widal test was considered as one that gave a reaction titre from $1 / 80$ and above in a single test.

\section{RESULTS AND DISCUSSION:}

Table 1 shows 95 sera samples from private medical laboratory, 83 samples from private clinics and 15 samples from Federal University of Technology Owerri (FUTO) community, making a total of 201 sera samples screened as positive on rapid slide agglutination test, while 61 samples showed positive agglutination test with titre $>1 / 180$ and this represents $24.4 \%$ of the entire individuals tested. This contradicts the report of Esohe et al. (2012) who reported $73.9 \%$ with signs compatible with typhoid fever among 234 patients tested in Ikare Akoka, Ondo state of Nigeria.

Table 2 shows the age distribution pattern of typhoid fever. The age of 26 to 35 years (27 cases) showed the highest positive result while the least positive result was found in the age group of 5 to 15 years (4 cases) amongst total of 61 samples that showed positive tube agglutination tests. This concurs with findings of Esohe et al. (2012) who reported 66 patients out of 173 patients 
Table 1. Frequency distribution of healthy individuals against positive typhoid fever cases.

\begin{tabular}{lcccc}
\hline Sampling location & $\begin{array}{c}\text { No. Of Healthy } \\
\text { individual }\end{array}$ & $\begin{array}{c}\text { Frequency of } \\
\text { Supposed Typhoid } \\
\text { fever sera samples }\end{array}$ & $\begin{array}{c}\text { No. Positive } \\
\text { Screening tests (\%) }\end{array}$ & $\begin{array}{c}\text { No. of confirmed } \\
\text { positive tube } \\
\text { agglutination (\%) }\end{array}$ \\
\hline FMC & - & 8 & $8(3.2)$ & $7(2.8)$ \\
Private medical laboratory & - & 98 & $95(38.0)$ & $26(10.4)$ \\
Private clinic & 60 & 84 & $83(33.2)$ & $30(12,0)$ \\
FUTO & 60 & - & $15(6.0)$ & $5(2.0)$ \\
Total & 190 & 201 & $61(24.4)$ \\
\hline
\end{tabular}

Total no of patients tested $=250, \mathrm{FMC}=$ Federal medical centre.

Table 2. Age distribution pattern of typhoid fever cases.

\begin{tabular}{cccc}
\hline Age (years) & No. tested & Frequency of Positive tube agglutination tests & \% Typhoid fever patients \\
\hline $5-15$ & 25 & 4 & 6.6 \\
$16-25$ & 68 & 12 & 19.7 \\
$26-35$ & 97 & 27 & 44.3 \\
$36-45$ & 32 & 13 & 21.3 \\
$46-60$ & 28 & 5 & 8.2 \\
Total & 250 & 61 & 100 \\
\hline
\end{tabular}

Table 3. Gender distribution pattern of typhoid fever cases.

\begin{tabular}{lccc}
\hline Gender & No tested & Frequency of Positive tube agglutination tests & \% Typhoid fever patients \\
\hline Male & 105 & 23 & 37.7 \\
Female & 145 & 38 & 62.3 \\
\hline
\end{tabular}

who tested typhoid fever positive to be within the range of 26 to 35 years while reports of Nicholas et al. (2010) and Parry (2005) showed that prevalence of typhoid fever in endemic areas is considered high in school-aged children and young adults. Older adults are presumably relatively resistant due to frequent boosting of immunity (Parry, 2005).

Table 3 defines the prevalence of S. Typhi infection amongst gender of the patients' symptoms. The highest typhoid positive result is shown in 38 female patients while 23 males representing 62.3 and $37.7 \%$, respectively. This may be due to the fact that females are more vulnerable to such disease due to poor health conditions and environmental factors associated to these women. This is mostly found amongst market women who are not aware of the mode of transmission of this disease due to poor level of education. The result is contrary to earlier report of lbekwe et al. (2008) who reported typhoid titres above 80 to occur more in male $3.7 \%$ against $3.6 \%$ of females.

Table 4 represents the distribution frequency of $S$. enterica serovar Typhi/Paratyphi antigens in positive patients. A total of 151 cases of typhoid fever somatic 'O' and ' $\mathrm{H}$ ' agglutinin titer levels were assessed; 31 (20.53\%) had an 'O' agglutinin titer level above 1:160 while10 patients $(6.62 \%)$ had an 'H' agglutinin titer level above. However, a significant number of typhoid cases was obtained by 'O' and ' $\mathrm{H}$ ' titers together 110 (72.85\%). Somatic $O$ antigens serologically were more common causes of typhoid fever in Owerri municipal council, with S. Typhi being the most prevalent with $34.4 \%$ patients being sero-positive for antibodies, S. Paratyphi B-H antigens closely followed with 16 positive typhoid fever patients, representing $26.2 \%$ prevalence in Owerri. The least was observed with $\mathrm{S}$. Paratyphi $\mathrm{C}-\mathrm{H}$ antigens showing $4.9 \%$ prevalence. Earlier study by Esohe et al. (2012) and lbekwe et al. (2008) proved somatic "O" antigens to be common cause of typhoid fever in different parts of Nigeria. Ibekwe et al. (2008) also reported S. Typhi 'O' to have shown positive titre of $39 \%$ in male and $10.7 \%$ in female when tests in apparently normal individuals were conducted.

Variation in geographic location is an important tool in the epidemiology of enteric fever and could help in 
Table 4. Distribution frequency of $S$. enterica serovar Typhi/Paratyphi antigens in positive patients.

\begin{tabular}{llcc}
\hline Antigen & Serotypes & No. of positive tests & \% positive test \\
\hline \multirow{4}{*}{ Somatic "O" } & Salmonella Typhi O & 21 & 34.4 \\
& Salmonella Paratyphi A-O & 15 & 24.6 \\
& Salmonella Paratyphi B-O & 6 & 9.8 \\
& Salmonella Paratyphi C-O & 8 & 13.1 \\
& & & \\
\multirow{5}{*}{ Flagella "H" } & Salmonella Typhi H & 10 & 16.4 \\
& Salmonella Paratyphi A-H & 11 & 18.0 \\
& Salmonella Paratyphi B-H & 16 & 26.2 \\
& Salmonella Paratyphi C-H & 3 & 4.9 \\
\hline
\end{tabular}

Total No. of positive enteric fever patients based on tube agglutination test $=61$.

Table 5. Survey of typhoid fever cases in Owerri.

\begin{tabular}{lccc}
\hline Months (2013) & FMC typhoid fever cases & $\begin{array}{c}\text { Private clinic } \\
\text { typhoid fever cases }\end{array}$ & $\begin{array}{c}\text { Private medical laboratories } \\
\text { typhoid fever cases }\end{array}$ \\
\hline January & 1 & 37 & 45 \\
February & 1 & 26 & 12 \\
March & 4 & 8 & 24 \\
April & 3 & 13 & 17 \\
Total & 8 & 84 & 98 \\
\hline
\end{tabular}

diagnosis. This means that some serotypes are known to be more prevalent in certain areas than in others due to exposure to modern facilities.

Table 5 shows the survey carried out on typhoid fever cases from hospitals located in Owerri Municipal council Imo state, Nigeria from January to April, 2013. Private medical laboratories recorded the highest number of patients diagnosed of the disease. The report agrees with previous reports of Erdem et al. (2004) who reported sampling of typhoid fever patient from outpatient clinics as 63.2 and $36.8 \%$ hospitalized patients. Raffatellu et al. (2008) also reported increase in the frequency of enteric fever with serovar Paratyphi $A$ showing a wider spread in some parts of the world while Asia has the highest incidence rates of typhoid fever. This may be attributed to self medication amongst the inhabitant of the city; similarly many private clinics operate with in-house medical laboratories. It was also observed that the Federal Medical Centre with qualified medical personnel had 8 patients diagnosed of the typhoid fever within the period under review. This frequency may be attributed to availability of modern scientific equipment in Federal Medical Centre unlike Private Medical Laboratories.

\section{Conclusion}

The frequency of survey made during this research stimulated the quest to prove whether all diagnosed of typhoid fever were actually suffering from the disease or related symptom that may be associated with latent clinical infection. From the total sample of 190 "Supposed typhoid fever patient" and 60 "healthy individual" tested, it was observed that only 61 representing $24.4 \%$ individuals were positive to Widal tube agglutination test. From this result, it can be deduced that most test carried out are rapid slide agglutination test which can give "false positive result" based on prolonged illness or non typhoid Salmonellosis. Also, most cases of malaria had often diagnosed and treated as typhoid fever due to inexperienced medical laboratory personnel and non availability of modern scientific equipment. Therefore, government should also embark on enlightenment campaigns for health workers and training sessions for most private medical laboratory owners. Also, it is important to create awareness on the importance of personal health hygiene and the risks associated with non compliance.

\section{REFERENCES}

Bhan MK, Bahl R, Bhatnagar S (2005). Typhoid and paratyphoid fever. Lancet 366:749-762.

Bhutta ZA, Hendricks KM (1996). Nutritional management of persistent diarrhea in childhood: a perspective from the developing world. J. Pediatr. Gastr Nutr. 22:17-37.

Buckle GC, Fischer Walker CL, Black RE (2012). Typhoid fever and paratyphoid fever: systematic review to estimate global morbidity 
and mortality, for 2010. J. Glob. Health. 2(1).

Crump JA, Luby SP, Mintz ED (2004). The global burden of typhoid fever. Bull World Health Organ 82:346-353.

Elsarnagawy D (1978). Viability of some Salmonella strains in Algerian eggs. Arch Inst Pasteur Alger 53:282-290

Erdem B, Güşen H, Suna G, Deniz G, Serpil E, Bülent S, Aysev AD (2004). Salmonella enterica serotypes and Salmonella infections: a multicenter study covering ten provinces in Turkey. Microb. Bull. 38(3):173-86

Esohe Al, Osazua F, Ajayi SA, Ebueku A, Igbinigbe (2012). Dual Infection with Typhoid and and Malaria in Febrile Patients in Ikare akoko, Nigeria. Int. J. Trop. Med. 7(1): 49-52.

Feasey NA, Archer BN, Heyderman RS, Sooka A, Dennis B, Gordon MA, Keddy KH (2010). Typhoid fever and invasive non-typhoid salmonellosis, Malawi and South Africa. Emerg. Infect. Dis. 16(9):1448.

Hook EW, Gurrant RL (1987). Salmonella infection: Harrison's Principles of Internal Medicine, 11th ed. McGraw Hill, Koga Kusha Ltd., Int. Student Edition.

Ibekwe AC, Okonko IO, Onunkwo AU, Donbraye E, Babalola ET, Onoja BA (2008). Baseline Salmonella agglutinin titres in apparently healthy freshmen in Awka, South Eastern, Nigeria. Sci. Res. Essay 3(9):225-230.

Kothari A, Pruthi A, Chugh TD (2008). The burden of enteric fever. J. Infect. Dev. Ctries. 2: 253-259.
Onunkwo AU, Nwankwo CH, Umolu DN (2001). Stochastic Appraisal of the Routine Sero-diagnostic method for Enteric Fever in Nigeria. J. Sci. Eng. Technol. 8(1): 2964-2973.

Olsen SJ, Pruckler J, Bibb W, Nguyen TM, Tran MT, Nguyen TM, Sivapalasingam S, Gupta A, Phan TP, Nguyen TC, Nguyen VC, Phung DC, Mintz ED (2004) Evaluation of rapid diagnostic tests for typhoid fever. J. Clin. Microbiol. 42: 1885-9.

Parry CM (2005).Epidemiological and clinical aspects of human typhoid fever: In 'Salmonella' Infections: Clinical, Immunological and Molecular Aspects, ed. Mastroeni P, Maskell D. Cambridge University Press. pp. 1-10.

Raffatellu M, Wilson P, Winter SE, Andreas J, Bäumler AJ (2008) Clinical pathogenesis of typhoid fever. J. Infect. Dev. Ctries. 2:260266.

Wait DA, Sobsey MD (2001) Comparative survival of enteric viruses and bacteria in Atlantic Ocean seawater. Water Sci. Technol. 43:139-142.

World Health Organization (WHO) (2008). Prepared for World Water Day 2001. Reviewed by staff and experts from the cluster on Communicable Diseases (CDS) and the Water, Sanitation and Health Unit (WSH). World Health Organization.

Yang J (2008) Enteric Fever in South China: Guangxi Province. J Infect Dev Countries 2: 292-297. 